\section{Miss, Mister, Doctor: how we are titled is of little consequence}

It is difficult to see any rhyme or reason in the titles and forms of address for British hospital doctors; there can be little doubt that the general public struggle to understand the 'rules'. Dentists are adding to the confusion in the high street by increasingly styling themselves as Doctor.

When referring a patient to the hospital, the general practitioner may say 'I am sending you to see a consultant', or a specialist, or a surgeon but when the patient arrives, what is the proper form of address? Is it Doctor or Mister? What is signified by these terms? The fact is that there are no rules, just rather obscure conventions. It remains a complete mystery to many patients and just when they begin to get the hang of it they are caught out again. At one point the rule seems simple. Surely all consultants are called Mister? Many believe so and state so authoritatively in the pub or on the Clapham omnibus. It held true and seemed consistent when a family member went to the hospital with her piles, a hernia or a breast lump. The doctors they met in the hospital were called Mister. Was it because they were consultants or specialists? No, it is because those were surgeons. Then along he goes with heart trouble. A coronary stent insertion is advised. Next thing the cardiologist appears all togged out, just like a surgeon, and you get it wrong again - this Miss is accustomed to being called Doctor. To the patient (and much of the British press) inserting a stent seems uncannily similar to an operation, but wrong again. Probably for no other reason than it is not being done by a card carrying surgeon, angioplasty is called an intervention (a percutaneous coronary intervention or $\mathrm{PCI}$ ).

A good history of how surgeons came to be called Mister is provided by the respected medical historian Irvine Loudon. ${ }^{1}$ Ibery and colleagues have surveyed the otolaryngologists to find out how they would prefer to be addressed, ${ }^{2}$ but would their patients know them better as ENT surgeons, and are either or both coterminous with the fashionable Head and Neck Surgeon? It is the patients who are at risk of being confused by these terms and titles. Consider, for example, the risk taken in addressing a consultant cardiologist as nurse. Patients have their own worries and do not need the added anxiety of making a faux pas. It merits our attention - perhaps there is a way we can unscramble ourselves to help them. It would be instructive to follow Ibery's lead and perform a properly structured poll - but of what patients would like, rather than what and way beyond our resources. So we will rely on our own experience - between us we have heard a lot of patients' questions, confusions and opinions.

We can start on fairly sure ground. In Britain, if someone is described as 'a doctor' there is broad agreement about what is intended. This is an individual who has passed a formal qualifying examination and is licensed by a National regulatory body after years of university education and training in a teaching hospital in what is regarded within our culture, and recognized throughout the world, as Western scientific or just 'modern' medicine. ${ }^{3}$ These doctors give advice about sickness and health and prescribe drugs. In any other sense the word is qualified — as in 'witch doctor'. The public and the other forms of practitioners have the good sense not to allow language to confuse them. They use terms such as healer, herbalist, and therapist and qualifiers such as traditional and alternative. Nobody is in any serious doubt about what we mean by a doctor, nor indeed by a dentist or a surgeon. From now on we will use the word doctor in this sense. The sense includes surgeons as being a type of doctor for most people. The title Mister raises a question for some but the standard of education, training and licensing are perceived as being at least those of a doctor.

The usage certainly does not cover those titled Doctor by virtue of having a $\mathrm{PhD}$. There may be some badinage about which is the 'proper doctor' but joking aside, we all know what is meant when the cry goes up 'Is there a doctor in the house?'. Dr Ian Paisley does not spring to mind, nor to his feet. There are plenty of Doctors but there is no confusion about which is which in most university departments. In the preclinical science departments we begin to see the need to specify in some practical classes, particularly where patients are involved. However, in hospital the title Doctor for someone who is not a doctor begins to cause confusion. The clinical psychologist, neurophysiologist, nurse or non-medically qualified manager with a $\mathrm{PhD}$ has a dilemma. They worked hard for the title and may well feel it was harder earned and more deserved than the courtesy title given to those who practise medicine on a couple of bachelor degrees. What are they to do? Put PhD after their name? Forgo the title? They rarely do and yet the use of the title Doctor, in a hospital setting, will mislead nearly all members of the public into thinking the title is medical. We come across Doctors in editing, management, politics, guideline development, health services research and scientific committees and the title is ambiguous. Few PhDs seem overly concerned about the possible confusion and in all of those fields it is their contribution not the camp they come from that matters.

We little islanders reflect on these issues, but the continent which always hosts The World Series, believes 
that all over the world children go to school in yellow buses, and can understand no currency other than the dollar, has its own ways which are as strange to us as we are to them. Doctor Denton Cooley (acclaimed by his followers as America's greatest surgeon) told his residents, you had better call him Mister Treasure, with just possibly a reference to Sidney Poitier's 'In the Heat of the Night' character who insisted on being addressed as Mr Tibbs, not just Virgil. In the USA the Doctor status was lost a long time ago. All dentists, osteopaths, podiatrists and veterinary surgeons are called Doctor and many other therapists besides. The title Doctor is largely devalued. To identify a doctor the public need to look for MD, often on car registration plates. Americans use the word physician to embrace all those we call doctors whereas in Britain it has a much narrower meaning: we broadly divide hospital doctors into two camps, the physicians and the surgeons. In the USA the title Professor is completely devalued and not used other than with sarcastic intent. There are so many tiers of assistant and associate professors, that when you have to specify 'full' professor, there is no point. On the other hand in Britain professors in hospitals are rare. For the happy few who have the title, it is so nice to be called 'Prof', a pleasing form of address, respectful yet cosily avuncular.

So what is a consultant? It still has a special cachet in British medicine or why would nurses want to be consultants? But in common usage it is meaningless. The travel agent and electricity board's automatic switchboard tells us 'all our consultants are busy' and architects, accountants, engineers, heating engineers and so on, all do a little consultant work in retirement. What does it mean? Nothing.

What is a specialist? A generation ago it was a term of respect as used by a GP but in the hospital where the general surgeon and general physician controlled the beds and in turn the hospital, generalists trumped specialists.

Words change their meaning. Euphemisms have to be replaced by new euphemisms. Spastic and cretin were medical words but in the mouths of school boys became terms of abuse so were replaced by cerebral palsy and congenital hypothyroidism, more difficult to mouth and not suited to invective. Status words are adopted by those who seek status. The expansion of Surgeon's Assistant is one such. While Lynne Truss was not looking, the apostrophe was dropped ${ }^{4}$ and Surgeon Assistant emerged. Take Nurse Consultant and drop the redundant word to make it manageable (you choose which one) and you can be anything you want to be. No wonder the surgeons (male at least) are happy to be Mister without needing to be reminded that once it meant Master. Female surgeons would prefer to be called Doctor than fail to be recognized as medically qualified. It really does not matter. Being a surgeon is doing what a surgeon does. How we are titled is of little consequence.

\section{Tom Treasure}

\section{Carol Tan}

Guy's Hospital, London SE1 9RT, UK

E-mail: Tom.Treasure@ukgateway.net

\section{REFERENCES}

1 Loudon I. Why are (male) surgeons still addressed as Mr? BMJ 2000; 321:1589-91

2 Ibery N. Do surgeons wish to become doctors? J R Soc Med 2005;99:in press

3 Le Fanu J. The Rise and Fall of Modern Medicine. London: Little Brown, 1999

4 Truss L. Eats, Shoots \& Leaves. London: Profile, 2003

Jonathan Osborne, in his open letter to Royal College Presidents ${ }^{1}$ makes many important points. However, he misses some of the fundamental reasons about the need for change in medical training. He denigrates the Royal Colleges for bowing to Government pressure and calls on us to halt the reforms.

It is important to recognize that medicine has changed and that methods of training which were appropriate 25 years ago are less so now. It is true that the consultant of the past was held responsible for a great deal more; but usually as a generalist with fewer highly specialist skills, than those in today's post Calman era. But they had to be. They were often appointed to either a single-handed or at best two-person practice and would be expected to not only be clinically competent to deal with a wide variety of conditions but also to undertake teaching, research and management. The practice of medicine has now changed from a situation where a single consultant was head of a large team of juniors to a much flatter structure with many more consultant members of a team. Between them this team is expected to provide the comprehensive range of abilities and skills previously provided by one or two people.

Tomorrow's Doctors, ${ }^{2}$ the booklet produced by the GMC in the early 1990s was one of the starting points for the recognition that medicine has now become so vast that no 